\title{
The role of vision and visual skills in archery*
}

\section{B Strydom and JT Ferreira}

Department of Optometry, University of Johannesburg, PO Box 524, Auckland Park, 2006 South Africa

<jferreira@uj.ac.za>

Received 25 November 2009; revised version accepted 3 March 2010

\begin{abstract}
The main purpose of this study were firstly to determine the most important visual skills applicable to archery and secondly to determine the norms for these visual skills necessary for an archer to perform at an elite level. Another goal was to compare our results with previous results for elite athletes, (determined by Buys in 2002). Twenty eight archers from different archery styles such as compound bow archery, recurve bow archery and traditional bow archery were used. Their visual skill norms were categorized as Superior, Above average, Average, Ineffective and Needs immediate attention.
\end{abstract}

The results indicated that visual acuity, contrast sensitivity, stereopsis, eye-hand coordination, eyebody coordination and visual response time may be the most important skills in archery. Other factors such as distance judging and the choice of monocular or binocular aiming has also been tested and discussed and norms for these tests were also established. (S Afr Optom 2010 69(1) 21-28)

Key words: visual skills, archery, visual skill norms, visual acuity, contrast sensitivity, stereopsis, eye-hand coordination, eye-body coordination, visual response time, distance judging, monocular and binocular aiming

\section{Introduction}

Archery, historically used in hunting for food and during warfare between rival countries, has developed through the years into a formidable sport ${ }^{1}$ with national and international competitive events throughout the world ${ }^{2}$. The sport of archery, especially bow hunting is a rapidly growing industry around the world. More specifically, in the USA the number of archers has increased with 5-8\% per year from 1988 to $1997 .{ }^{3}$ Vision is the most dominant sense, with $70 \%$ of all sensory receptors in the eye. Vision, with components such as visual skills, contributes up to $80 \%$ of information obtained $^{4}$. Sports vision can be defined as the study of the visual abilities that are required in recreational and competitive sports, as well as the development of visual strategies for improvement of accuracy, stamina, consistency and hence performance of the visual system". According to Reichow and Stern6: "Sports vision encompasses performance orientated comprehensive vision care programmes involving education, evaluation, correction, protecting, and enhancement of an athlete."

The involvement of vision, in any sport, is of paramount importance. The role of specialized sport vision practitioners may play an important role in either screening or correcting of athletes with visual defects and or help the athletes to perform 7 . At the 1994 Olympic Games in Lillehammer, from the 342 athletes representing 46 countries and ranging in age from 16 to 41, more than $171(50 \%)$ had never received a 
comprehensive visual examination ${ }^{8}$. This corresponds with previous results from Garner ${ }^{9}$ who concluded that a significant amount of elite athletes compete in their specific sports with uncorrected visual defects. This may be because the sports they participate in are perhaps of low visual demand, or they compensate with higher functioning of other skills ${ }^{10}$, or they may be performing below their true potential.

According to Carlson ${ }^{11}$ certain visual skills play a more important role in archery. Eye motility, speed of recognition time, ability to see in dim illumination, dynamic visual acuity, peripheral awareness, spatial localization, depth perception and eye-hand/foot coordination are not the most important factors to consider in archery ${ }^{11}$. However, according to Gardner and Sherman ${ }^{12}$, visual skills that may be important in archery are visual acuity, eye-hand coordination, visual adjustability and central-peripheral awareness.

This uncertainty regarding the important visual skills in the sport of archery emphasizes the necessity for further investigation. There are many different sports, and it is impossible to have expert knowledge about every sport specific ${ }^{7}$. Coffey and Reichow ${ }^{13}$, developed the Pacific Sports Visual Performance Profile (PSVPP) and provided guidelines for elite athlete evaluation. Buys ${ }^{4}$ suggested further improvements to increase the efficiency of elite athlete evaluation. Buys ${ }^{4}$ also came to the conclusion that specific norms should be established for each sport. Most researchers agree that there is a need for more information regarding vision and sport and this may be the way forward to utilize sports vision to its full potential in the future.

The primary aim of this study was to determine the most important visual skills in archery and the appropriate norms for these mentioned visual skills, when used in archery. The visual skills were divided into five categories, namely Superior, Above average, Average, Ineffective and Needs immediate attention. The visual skills norms were also compared to the norms established by Buys ${ }^{4}$ for elite athletes.

\section{Method}

Twenty eight archers $(N=28)$ were used in the study. All the archers used in this study was randomly selected and consisted of eleven compound bow archers, eight recurve bow archers and nine traditional bow archers. The archers differed in experience from beginners to experts and their ages ranged from 12 58 years. Twenty one male archers and seven female archers participated.

To define the norms for the different visual skills measured, two standardized methods from Buys ${ }^{4}$ were used, namely the percentage method and the mean and standard deviation method.

\section{Mean and Standard Deviation method}

The Average group was calculated by addition of the standard deviation to the mean value. The Superior group was calculated by adding another standard deviation to the average value. For example if the mean value for a visual skill was 40 , and the standard deviation 10, then the Average group would be between 40 and 50. The Above average group would be calculated by adding another standard deviation group to the maximum value of the average group. In this example, the Above average group would be between 50 and 60 . The Superior group would be any value higher than the Above average value and for the example used, higher than 60 . The Ineffective group would be calculated by subtraction of the standard deviation from the minimum mean value. The example used above would calculate the Ineffective group to be between 30 and 40 . Buys ${ }^{4}$ further stated that he did not add and subtract the standard deviation from the mean for calculation of the Average group. He did this to keep the groups more or less the same size, and for the Average group he only adds the standard deviation to the mean value. Subtraction of the standard deviation from the mean value was categorized as the Ineffective group. The Needs immediate attention group would be any value lower than the lowest value of the Ineffective group.

\section{Percentage method}

The Superior group would be the top ten percent of the group. The Above average group would be from 90 to 70 percent. From 70 to 50 percent would be the Average group and the remaining 50 percent 
would be divided equally. The Ineffective group would be categorized from 50 and 25 percent and the Needs immediate attention from 25 - 0 percent. The appropriate method was used on the same principle as Buys ${ }^{4}$ did. This means that if the results obtained for a specific visual skill had minimum and maximum values,' the percentage method was used. The mean and standard deviation method was used for the remaining of the visual skills. Archers were only allowed to use their refractive compensation if they were already using appropriate compensation for their sport.

\section{Results}

The statistical analysis was conducted by STATKON, the statistical consultation service at the University of Johannesburg. The visual skills found to be the most important in archery were static visual acuity, contrast sensitivity, stereopsis, eye-hand coordination, eye-body coordination and visual response time. Distance judging and accuracy: monocular and binocular were two new tests conducted specifically for archery.

Table 1: The norms for static visual acuity (decimal notation) are indicated. (A Snellen VA chart was used at three metres and results were converted to visual acuities at six metres.) The results in brackets are the results obtained by Buys ${ }^{4}$.

\begin{tabular}{|l|l|l|l|}
\hline $\begin{array}{l}\text { STATIC } \\
\text { VISUAL } \\
\text { ACUITY }\end{array}$ & RIGHT & LEFT & BINOCULAR \\
\hline SUPERIOR & $\begin{array}{l}<1.25 \\
(>1.76)\end{array}$ & $\begin{array}{l}<1.28 \\
(>2.00)\end{array}$ & $\begin{array}{l}<1.29 \\
(>1.62)\end{array}$ \\
\hline ABOVE & $1.11-1.25$ & $1.12-1.28$ & $1.12-1.29$ \\
AVERAGE & $(1.76-1.30)$ & $(2.00-1.25)$ & $(1.62-1.30)$ \\
\hline AVERAGE & $0.95-1.10$ & $0.94-1.11$ & $0.93-1.11$ \\
& $(1.28-1.0)$ & $(1.22-1.0)$ & $(1.30-1.0)$ \\
\hline INEFFECTIVE & $0.94-0.80$ & $0.77-0.93$ & $0.75-0.92$ \\
& $(0.98-0.75)$ & $(0.98-0.78)$ & $(0.98-0.85)$ \\
\hline NEEDS & & & \\
IMMEDIATE & & & $<0.75(0.85)$ \\
\hline ATTENTION & $<0.80(<0.75)$ & $<0.80(0.78)$ & $<$ \\
\hline
\end{tabular}

The results for the static visual acuity for the left eye, right eye and both eyes indicate that the norms obtained for archery are lower compared to the results of the elite athletes Buys ${ }^{4}$ tested. The results obtained binocularly were the greatest. Although the archers achieved lower scores than the elite athlete's from Buys' study ${ }^{4}$, the majority of archers achieved visual acuity values of 1.0, which may indicate the importance of this visual skill in archery.

Table 2: The norms for contrast sensitivity with the use of the Functional Acuity Contrast Test. The results in brackets are the results obtained by Buys ${ }^{4}$.

\begin{tabular}{|l|l|}
\hline CONTRAST SENSITIVITY & ROWS INDENTIFIED CORRECTLY \\
\hline SUPERIOR & Correctly identifying all 5 rows \\
\hline ABOVE AVERAGE & \\
\hline AVERAGE & $\begin{array}{l}\text { Identifying Row D correctly and Row A, Row B, Row C and } \\
\text { Row E up to } 8 \text { Correctly }\end{array}$ \\
\hline INEFFECTIVE & Row B, Row C and Row D up to 8 with Row A and E up to 7 \\
\hline $\begin{array}{l}\text { NEEDS IMMEDIATE } \\
\text { ATTENTION }\end{array}$ & $\begin{array}{l}\text { Row B, C and D any value below 8, and Row A and Row E } \\
\text { any value below } 7\end{array}$ \\
\hline
\end{tabular}

The norms obtained for contrast sensitivity was lower than the norms obtained by Buys ${ }^{4}$ for elite athletes.

Table 3: The norms for stereopsis with the use of a Randot Stereo Test. The results in brackets are the results obtained by Buys ${ }^{4}$.

\begin{tabular}{|l|l|}
\hline STEREOPSIS & SECONDS OF ARC \\
\hline SUPERIOR & $20(20)$ \\
\hline ABOVE AVERAGE & $25-50(20)$ \\
\hline AVERAGE & $50-70(20)$ \\
\hline INEFFECTIVE & $70-160(25-30)$ \\
\hline $\begin{array}{l}\text { NEEDS IMMEDIATE } \\
\text { ATTENTION }\end{array}$ & $>160(>30)$ \\
\hline
\end{tabular}

The norms obtained indicated that the archers achieved lower values than the elite athletes tested by Buys ${ }^{4}$.

Table 4: The norms for eye-hand coordination with the use the Computerized Wayne Saccadic Fixator. The results in brackets are from Buys 4 .

\begin{tabular}{|l|l|}
\hline $\begin{array}{l}\text { EYE-HAND } \\
\text { COORDINATION }\end{array}$ & NUMBER OF LIGHTS \\
\hline SUPERIOR & $>49(>52)$ \\
\hline ABOVE AVERAGE & $41-48(44-52)$ \\
\hline AVERAGE & $33-40(36-43)$ \\
\hline INEFFECTIVE & $25-32(28-35)$ \\
\hline $\begin{array}{l}\text { NEEDS IMMEDIATE } \\
\text { ATTENTION }\end{array}$ & $<25(<28)$ \\
\hline
\end{tabular}

The results indicate that the norms obtained for the 
archers were again lower than those obtained by Buys ${ }^{4}$ for elite athletes.

Table 5: The norms for eye-body coordination with the use a balance board connected to the Computerized Wayne Saccadic Fixator. The results in brackets are the results obtained by Buys ${ }^{4}$.

\begin{tabular}{|l|l|}
\hline $\begin{array}{l}\text { EYE-BODY } \\
\text { COORDINATION }\end{array}$ & NUMBER OF LIGHTS \\
\hline SUPERIOR & $>48(>37)$ \\
\hline ABOVE AVERAGE & $39-47(32-37)$ \\
\hline AVERAGE & $30-38(27-31)$ \\
\hline INEFFECTIVE & $22-29(22-26)$ \\
\hline $\begin{array}{l}\text { NEEDS } \\
\text { IMMEDIATE } \\
\text { ATTENTION }\end{array}$ & $<22(<22)$ \\
\hline
\end{tabular}

The norms obtained for the archers were higher than those of the elite athletes tested by Buys ${ }^{4}$. This may be an indication that this visual skill is highly important in archery.

Table 6: The norms for visual response time with the use of the wayne saccadic fixator. The results in brackets are from Buys ${ }^{4}$.

\begin{tabular}{|l|l|l|}
\hline VISUAL RESPONSE TIME & SECONDS & SECONDS \\
\hline & RIGHT HAND & LEFT HAND \\
\hline \multirow{2}{*}{ SUPERIOR } & $<0.180$ & $<0.250$ \\
& $(<0.268)$ & $(<0.247)$ \\
\hline \multirow{2}{*}{ ABOVE AVERAGE } & $0.340-0.180$ & $0.250-0.380$ \\
& $(0.268-0.397)$ & $(0.247-0.378)$ \\
\hline & $0.341-0.505$ & $0.381-0.513$ \\
AVERAGE & $(0.398-0.526)$ & $(0.379-0.509)$ \\
\hline & $0.506-0.670$ & $0.514-0.650$ \\
INEFFECTIVE & $(0.527-0.656)$ & $(0.510-0.640)$ \\
\hline NEEDS IMMEDIATE & $>0.670$ & $>0.650$ \\
ATTENTION & $(>0.656)$ & $(>0.640)$ \\
\hline
\end{tabular}

The norms obtained for the visual response time with the right hand was higher than those of the elite athletes tested by Buys ${ }^{4}$. The visual response time (left hand) was lower than the norms obtained by Buys ${ }^{4}$ for elite athletes.

\section{Distance judging}

The range judging test was a test designed to evaluate the ability of the archer to judge the distance of objects placed at unknown distances. This is an extremely important ability that the archer needs especially when bow hunting or shooting specific classes in compound archery.

Distance judging was evaluated by placing four objects, in this case tennis balls, in an open area to simulate the shooting environment, and the athlete standing next to the examiner at a given point. The archer was then instructed to estimate the distances of the specific objects. The time limit was 30 seconds per object which after that the archer had to write down the estimated distance. The distance was judged in yards, as this is the most common system used in archery. The correct distance of the object was measured with an electronic Nikon 440 range finder before hand. The distances used were 17 yards $(16 \mathrm{~m}), 22$ yards $(20 \mathrm{~m}), 32$ yards $(29 \mathrm{~m})$ and 55 yards $(50 \mathrm{~m})$.

Table 7: The norms for distance judging at 17, 22, 32 and 55 yards are indicated.

\begin{tabular}{|l|l|l|l|l|}
\hline $\begin{array}{l}\text { ERRORS } \\
\text { (MEASURED } \\
\text { IN YARDS) }\end{array}$ & $\begin{array}{l}\text { DISTANCE } \\
\text { JUDGING } \\
\text { AT 17 } \\
\text { YARDS }\end{array}$ & $\begin{array}{l}\text { DISTANCE } \\
\text { JUDGING } \\
\text { AT 22 } \\
\text { YARDS }\end{array}$ & $\begin{array}{l}\text { DISTANCE } \\
\text { JUDGING } \\
\text { AT } 32 \\
\text { YARDS }\end{array}$ & $\begin{array}{l}\text { DISTANCE } \\
\text { JUDGING } \\
\text { AT 55 } \\
\text { YARDS }\end{array}$ \\
\hline SUPERIOR & $<0.55$ & $<2.02$ & $<1.16$ & $<7.00$ \\
\hline $\begin{array}{l}\text { ABOVE } \\
\text { AVERAGE }\end{array}$ & $0.55-2.79$ & $<2.02$ & $<1.16$ & $<7.00$ \\
\hline AVERAGE & $2.80-5.05$ & $2.01-6.75$ & $5.61-10.06$ & $19.25-31.50$ \\
\hline INEFFECTIVE & $5.06-7.30$ & $6.76-11.48$ & $10.07-14.51$ & $31.51-43.76$ \\
\hline $\begin{array}{l}\text { NEEDS } \\
\text { IMMEDIATE } \\
\text { ATTENTION }\end{array}$ & $>7.30$ & $>11.48$ & $>14.51$ & $>43.76$ \\
\hline
\end{tabular}

In general it can be seen that the archers made smaller errors where objects were closer to them. The greater the distance became, the greater the error made. Distance judging at 22 yards, 32 yards and 55 yards resulted in the Above average group to be ignored due to the same results than the Superior group.

\section{Accuracy: monocular versus binocular aiming}

The binocular versus monocular aiming test was conducted with the compound and recurve bow archers, to determine if there was differences between the two methods of aiming, and whether this may be of any significance. This could aid in reducing the different coaching beliefs that do exist. This test was not 
done for the traditional archers, as traditional archers do not use a sight. The archer was instructed to aim the way he or she would usually aim, thus either binocularly or monocularly. The archer was then instructed to shoot at a white paper sheet that was 90 $\mathrm{mm}$ in height and $50 \mathrm{~mm}$ in width. Three arrows were shot and the distance was 20 yards $(18 \mathrm{~m})$. The researcher then observed if the shot was made binocularly or monocularly and recorded this finding. This aided the researchers in determining if the archer normally aims monocularly or binocularly. Next, the archer's non-dominant, non-aiming eye was closed with an eye-cap that did not interfere with his normal archery routine to determine the accuracy if aiming monocularly. After the three shots the distances between the centre of the two "outside" shafts of the arrows shot was measured and recorded in millimeters under "monocular shooting". The archer was then instructed to keep both eyes open and to shoot another three arrows in this manner, to determine the accuracy if aiming binocularly. After the three shots the distances between the centre of the two "outside" shafts was again measured and recorded in millimeters under "binocular aiming".

Table 8: The norms for accuracy: monocular and binocular aiming.

\begin{tabular}{|l|l|l|}
\hline $\begin{array}{l}\text { ACCURACY } \\
\text { (IN MILLIMETRES) }\end{array}$ & MONOCULAR & BINOCULAR \\
\hline SUPERIOR & $<14.43$ & $<58.74$ \\
\hline AVERAGE & $52.12-89.81$ & $58.74-124.29$ \\
\hline INEFFECTIVE & $89.82-127.50$ & $124.30-189.84$ \\
\hline $\begin{array}{l}\text { NEEDS IMMEDIATE } \\
\text { ATTENTION }\end{array}$ & $>127.50$ & $>189.84$ \\
\hline
\end{tabular}

In general the archers achieved better results and accuracy with monocular aiming compared to binocular aiming.

\section{Discussion}

\section{Static Visual acuity}

According to Grosvenor ${ }^{14}$, visual acuity can be defined as the resolving power of the eye or the ability of the eye to see two separate objects as separate. Visual acuity almost always refer to foveal visual acuity and may differ between individuals with different illumination, different distances, charts and different letters sizes ${ }^{14}$. Static visual acuity is used more often than dynamic visual acuity. The best-achieved visual acuity may be one of the most important factors in archery ${ }^{11}$. Calculation of the norms for static visual acuity was done using the mean and standard deviation method, as done by Buys ${ }^{4}$. Although the archers achieved lower scores than the elite athletes tested by Buys ${ }^{4}$ it may be due to the testing distance being three metres, due to practical issues, and this restricted the archers to score higher scores than 1.0. This is confirmed by 22 archers (right eye), 23 archers (left eye) and 22 archers (binocular) who achieved scores of 1.0. Although the archers achieved lower scores than the elite athlete's from Buys's study, the majority of archers achieved visual acuity values of 1.0 which may indicate the importance of this visual skill in archery. Future investigation at six metres may show that archers do have the same or may achieve even greater scores than elite athletes.

\section{Contrast Sensitivity}

A definition of contrast sensitivity would be the ratio of the difference between the maximum and minimum luminance of a testing target or stimulus, divided by the sum of the maximum and minimum luminance ${ }^{14}$, or the measurement of contrast sensitivity reflects the least amount of contrast that is needed for detection of a visual stimulus. This skill can be affected by poor illumination, age ${ }^{14}$, eye conditions such as corneal edema due to contact lenses, or dirty glasses as well as deposited contact lenses. The reduction in contrast sensitivity may lead to reduced visual performance and hence poor sporting performance ${ }^{7}$. Buys ${ }^{4}$ stated this skill may be of utmost importance in sport, such as target shooting where clarity and detail of a target is highly important. The test was done using the Functional Acuity Contrast Test (FACT). This test required the archer to determine the orientation of five different rows (row A - row E) with different spatial frequencies. Row A had the lowest spatial frequency and Row $\mathrm{E}$ the highest and in each row the contrast was reduced from left to right. The orientation was either slanting right or left or vertical. The percentage method was used to determine the norms for this skill. The results indicated that the norms was lower than the results obtained for elite athletes, as obtained by Buys ${ }^{4}$. The connection between visual 
acuity and contrast sensitivity is of great importance and therefore contrast sensitivity may be regarded as an important visual skill in archery.

\section{Stereopsis}

Stereopsis would be the ability to perceive depth due to retinal disparity ${ }^{14}$. This means when an object point does not stimulate corresponding retinal points for both eyes and it actually stimulates non-corresponding points the result would be stereopsis. For this to take place binocular vision must be intact ${ }^{4}$. Buys ${ }^{4}$ stated that stereopsis is important in sport with moving objects or targets. The importance of stereopsis in archery may be linked to the distance judging of targets, if the distance is unknown.

The percentage method was used to determine the norms for stereopsis and the results showed that the norms was lower than the elite athletes from Buys ${ }^{4}$ study. This may have been due to the small sample size and bias that over emphasizes the few athletes that had a reduction in visual acuity. It may also have been due to the archers that were presbyopic and had difficulty with the test due to reduced clarity with reading. Nevertheless, the importance of stereopsis may be an important visual skill in archery, depending on the discipline it will be used for. In competitive events organized by the International Bowhunting Organisation (IBO) the distances are unknown and must be judged, and thus this visual skill may be of great importance.

\section{Eye-hand coordination}

Paillard ${ }^{15}$, said that eye-hand coordination is a "perceptual-motor skill involving the integration and processing in the central nervous system of visual and tactile information so that purposeful motor movements can be made". According to Ferreira ${ }^{16}$, "eye-hand coordination determines the effectiveness of a perceptual motor response to a visual stimulus". Sherman ${ }^{17}$ also mentioned that eye-hand coordination testing results are higher in sports such as baseball, hockey and basketball, where fast visual reaction to a moving object is more so important than in sports such as archery, bowling and golf.

The mean and standard deviation method was used to obtain the norms for this visual skill. The results revealed that the archers achieved lower scores than the elite athletes from Buys'4 study, although the difference was not great. This may suggest that the importance of eye-hand coordination cannot be ignored in the sport of archery as most of the archers did achieve good results with the testing of this visual skill.

\section{Eye-body coordination}

This skill is involved in the ability of the athlete to adjust his/her balance in response to a visual stimulus ${ }^{7}$. This is normally a skill developed through exercising, and is difficult to isolate it for attendance ${ }^{2}$. According to Ferreira ${ }^{16}$ this visual-motor skill requires integration from the three most important senses used in the performance of motor skills. These senses would be equilibrium, pro-prioception and vision. According to Long and Haywood ${ }^{18}$ stability plays an important role in the performance in archery. Mason and Pelgrim ${ }^{19}$ concluded that the accuracy in archery is related to an archer's movement of his or her centre of pressure on the ground just before releasing the arrow. This may well be one of the most important visual skills to consider in archery. The mean and standard deviation method was used to obtain the results for eye-body coordination. The results revealed that interestingly the archers norms was higher for this visual skill than the elite athletes tested by Buys ${ }^{4}$. Due to eye-body coordination being linked to balance and stability, this obtained results confirms the statements of Long and Haywood $^{18}$ as well as Dillman ${ }^{20}$ who emphasized the importance of stability in the sport of archery. This however may contradict the statement of Gardner and Sherman ${ }^{7}$ mentioning that this skill is not important in archery. Eye-body coordination may be the most important visual skill in archery.

\section{Visual Response Time}

According to Gardner and Sherman ${ }^{21}$, the term visual reaction time is a misnomer as this visual skill is in fact the motor response of an athlete tested to a visual stimulus. The Wayne saccadic fixator is preferred instrument used to test the horizontal visual reaction time. The left- and right hand is recorded individually. The athlete was positioned in front of the board and asked to press the light at the nine o' clock position, with the right hand, when ready. The 
athlete then had to, as quickly as possible press the light at the 3 o' clock position. This was done for the left hand as well. The quickest time (seven trials for each hand was allowed) was recorded as the visual response time for the specific hand. If there is a major difference between the dominant and non-dominant hand, it should be recorded ${ }^{2}$.

According to Buys 4 , visual response time is an important skill in dynamic- and static sport types. The speed of reaction to a visual stimulus is of utmost importance in dynamic sports, but the visual response time in static sports is important when the timing of a motor reaction must be linked to a specific imagery state or attentional focus. Lastly, according to Davis, Kimmet, Auty 22 visual response time is a very important skill in sport such as boxing and karate, but not in sport such as shooting or archery.The norms for visual response time of the archers were calculated by using the 'mean and standard deviation' method. The visual response time results for the right hand was higher than those achieved by the elite athletes in Buys' study 4 , but the left hand's results were lower, although they did not differ greatly from the results obtained by Buys ${ }^{4}$. This may be due to 27 out of the 28 archers that were right hand dominant. Increasing the number of left hand dominant archers may indicate a similar scenario compared to the right hand visual response time. Altogether visual response time may be regarded as an important visual skill in archery.

\section{Distance judging}

This test was conducted as an archery specific test. Distance judging was evaluated by placing four objects (tennis balls), in an open area, to simulate the shooting environment, and the athlete standing next to the examiner at a given point. The results revealed that the greater the distance, the greater the margin of error made. The judging of the object at 17 yards had the smallest margin of error and the judging of the object at 55 yards had the greatest margin of error. This may be due to a lack of experience with judging distance or the lack of practicing the skill of judging depth due to use of electronic aids, such as the Nikon 440 range finder.

\section{Accuracy: monocular versus binocular aiming}

The binocular versus monocular aiming test was conducted with the compound and recurve bow archers to determine if there was a difference between the two methods of aiming, and if this may be of any significance. This will help in coaching discrepancies that may exist. This test was not done for the traditional archers, as traditional archery do not use any sights to aim. The archer was instructed to aim the way he or she would usually aim, thus either binocular or monocular. The archer was then instructed to shoot at a white paper sheet that was $90 \mathrm{~mm}$ in height and $50 \mathrm{~mm}$ in width. Three arrows were shot and the distance was 20 yards $(18 \mathrm{~m})$. The researcher then observed if the shot was conducted binocular or monocular and recorded this. Next, the archer's nondominant, non-aiming eye was closed with an eyecap that did not interfere with his normal archery routine. After the three shots the distances between the centres of the two "outside" shafts of the arrows shot was measured, and then recorded in millimeters under "monocular shooting". The archer was then instructed to keep both eyes open and to shoot another three arrows in this manner. After the three shots the distances between the centres of the two "outside" shafts was again measured, and then recorded in millimeters under "binocular aiming". The results achieved revealed that it appear to be more beneficial to aim monocularly. The compound bow group achieved better scores than the recurve group for both the monocularand binocular-aiming. This may however have been due to difference in technique, equipment and skill involved being of greater difficulty when using the recurve bow. It must be said however that one archer achieved a score of $305 \mathrm{~mm}$ aiming binocular, and with this result excluded the results may have been different. Future investigation with a greater sample size may be of great interest.

\section{Conclusion}

The primary aim of the study was to determine the most important visual skills used in archery. This was achieved together with the second goal to determine archery specific norms for these determined visual skills. The study revealed that eye-body coordination may be one of the most important skills to 
consider and that balance and stability should not be under-estimated in archery. Although the norms established were mainly lower than those of the elite athletes from Buys's study 4 , it may be due to a lack of experience of some of the archers. Further studies using greater sample sizes or only elite archers may highlight the importance of these visual skills on a greater level. The question of whether visual training of these visual skills may improve the performance of the athletes remains unanswered and could lead to further studies.

\section{Acknowledgements}

The authors would like to thank all the archers and coaches for their time, effort and support regarding this study.

\section{References}

1. Ergen E, Hibner K. Sports Medicine and Science in Archery. Turkey: Hospitals Publishing House, 2004 pp1-2.

2. http://www.archery.org, Federation Internationale De Tir A L'Arc, date accessed: 19/03/2008.

3. Archery Manufacturers and Merchants Organization. The Facts about Bow Hunting and Target Archery. pp2-36.

4. Buys JHC. The Development of Norms and Protocols in Sports Vision Evaluations. Masters Thesis, Rand Afrikaans University, Johannesburg, South Africa, 2002.

5. Daune K, Darlene AK. The impact of vision and vision training on sports performance. Journal of Physical Education, Recreation and Dance 199723 63- 71.

6. Reichow AW, Stern NS. Optometric trends in sports vision. Optometric Extension Program Foundation. Curriculum II. 198659 355-368.

7. DFC Loran, CJ MacEwan. Sports Vision. London: Butterworth and Heinemann, 1995.

8. Olympic Vision Centre, Lillehammer. Findings of the Bausch \& Lomb Survey. 1994. In: DFC Loran and CJ MacEwan. Sports Vision. London: Butterworth Heinemann, 1995.

9. Garner AI. An overlooked problem: athlete's visual needs. Physician and Sports Medicine 1977 5 74-82.

10. Neil Murray, (personal communication). In: DFC Loran and CJ MacEwan, Eds. Sport Vision. London: Butterworth Heinemann, 1995.

11. Carlson NJ. Sports Vision Guidebook. The American Optometric Association: Sports Vision Section 19841 1-11.

12. Gardner JJ, Sherman A. Vision requirements in sport. In: DFC Loran and CJ MacEwen, Eds. Sports Vision. London: Butterworth-Heinemann, 1995 pp22-36.
13. Coffey B, Reichow AW. Optometric evaluation of the elite athlete: The Pacific sports visual performance profile. Problems in Optometry 19901 32-58.

14. Grosvenor T. Primary Care Optometry, 4th Edition. Oxford: Butterworth Heinemann, 2002.

15. Paillard J. Basic neuro-physiological structures of eye hand coordination. Development of Eye-hand Coordination 1990 26-74.

16. Ferreira JT. Sports Vision and Rugby. Department of Optometry, Rand Afrikaans University, 2001 pp1-16.

17. Sherman A. A method of evaluating eye-hand coordination and visual reaction time in athletes. Journal of American Optometric Association 198354 801-802.

18. Long WS, Haywood KS. The optical characteristics of aiming scopes in archery. Journal of the American Optometric Association 199061 777-781.

19. Mason BR, Pelgrim PP. Body Stability and Performance in Archery. Excel 19863 17-20.

20. Dillman CJ. Summary of Biomechanical Investigations in Archery. Unpublished Manuscript. Biomechanics and Computer Services Department, Olympic Complex, Colorado Springs, 1983.

21. Sherman A, Gardner JJ. Vision requirements in sport. In: DFC Loran and CJ MacEwen, Eds. Sports Vision. London: Butterworth and Heinemann, 1995 pp22-36.

22. Davis D, Kimmet T, Auty M. Physical Education: Theory and Practice. Melbourne: MacMillan, 1986 pp269-291 